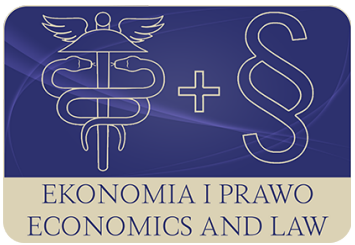

EKONOMIA I PRAWO. ECONOMICS AND LAW

Volume 19, Issue 1, March 2020

p-ISSN 1898-2255, e-ISSN 2392-1625

www.economicsandlaw.pl

EKONOMIA I PRAWO
ECONOMICS AND LAW

ORIGINAL ARTICLE

received 13.07.2019; revised 11.02.2020; accepted 31.03.2020

Citation: Zboroń, H. (2020). Sharing economy in axiological perspective. Ekonomia i Prawo.

Economics and Law, 19(1): 187-201. doi:10.12775/EiP.2020.013.

\title{
Sharing economy in axiological perspective
}

\author{
HALINA ZBOROŃ \\ Poznań University of Economics and Business, Faculty of Economics, Department of Sociology \\ and Business Ethics, al. Niepodległości 10, 61-875 Poznań, Poland \\ $\square$ halina.zboron@ue.poznan.pl \\ (D) orcid.org/0000-0002-8399-6709
}

\begin{abstract}
Motivation: The issue of sharing economy is the subject of a broad debate in the circle of politicians and economists who see it as an opportunity for boosting economic development. Simultaneously, there have been discussions about non-economic significance of this phenomenon and its impact on other areas of social life.

Aim: The aim of this paper is to show that the dispute concerning the values for this area of phenomena is mainly a result of lack of unresolved issues related to an adopted axiological perspective. The author's intention is to present argumentation supporting the thesis that the term ,sharing economy' may by referred to two - relating to various normative

beliefs - categories of social phenomena: business practice and social movement.

Results: Inclusion of various axiological contexts leads to diverse characteristics of the phenomena belonging to the sharing economy practice and the identification of their social significance.
\end{abstract}

Keywords: sharing economy; entrepreneurship model; social movement; axiology JEL: Al3; L31; L33; O35

\section{Introduction}

As a research subject and a field of social practice, the sharing economy is now an area of interest for researchers, politicians, publicists and social change leaders. A significant increase in the number of references - both in scientific publications and reports - to the terms associated with the issue of sharing economy indicates that this concept becomes these days an important social 
area. It is obviously related to a rapid development of the sharing economy practice indicated by an increasing share of subjects (individuals and organizations) in such type of activities, which has an obvious impact on the popularization of knowledge of this topic ${ }^{1}$. Together with an increase in scale of this phenomenon, there is an increase in a number of people attempting to explain this phenomenon - both on scientific and outreach level. A critical reflection is also taken regarding how those issues shall be analysed (cf: Curtis \& Leher, 2019). A special interest is noted in economics since the sharing economy is treated as a new business model belonging to the area of new economy -4.0 economy (the fourth technological revolution). It is predicted that there will be a rapid development of the sharing economy - for instance, PwC (2016) foresees that in 2025 the global revenue generated by this business model will amount to USD 335 billion dollars in financial, transport and hotel services, tourism and staffing. Such predictions are supported by the statistical data that shows an increase in interest in the offers classified as the sharing economy phenomena: in 2018, $54 \%$ of the UK's population used those offers, $47 \%$ of the USA's population and $60 \%$ of the PRC's population (Statista, 2019). An increasing economic importance of innovative solutions is based mainly on customers' and consumers' positive feedback. They appreciate a widespread availability and the ease of use of the offered possibilities, and an open access to goods and services. In 2015, The European Commission started the groundwork to create proper legal regulations, considering the sharing economy as a chance for boosting the economic development. In 2016 instead, the appointed commission presented a document in which both the specific characteristics of the sharing economy phenomena and the needs for creating regulatory issues specifying the areas of responsibility of parties involved were described. In particular, it relates to a decision about which of identified types of activity shall meet the criteria for conducting a business activity. It is worth to notice that this is one of the most difficult problems that needs solving. Many of taken innovative solutions under the sharing economy do not fit into the classical models of entrepreneurship activities and go beyond the framework of legal regulations.

\section{Methods}

This paper features theoretical aspects and it presents a critical analysis of the scientific discourse concerning the sharing economy: definition, function and social significance. The considerations are carried out within a cognitive perspective of cultural constructivism, according to which the reality is socially created and the world we consider in our normal experience as objectively existing, that is existing independently from human activity, is in fact a construct generated by collective experience. The experience of reality is a cultural phenomenon, which means that culture both enables and determines its process

${ }^{1}$ According to PWC (2016), 40\% of the adult Polish population identifies with the most common types of activities within collaborative/sharing economy. 
as well as its result. Within these considerations, it is assumed that cognitive results, which are obtained in the analysed texts, are conditioned by an adopted axiological perspective. Therefore, a reconstruction of normative contexts was applied, to which considerations regarding the sharing economy are referred.

Based on the analysis of texts on the subject of sharing economy, it can be shown that among their authors there are significant discrepancies as to its assessment. Furthermore, for a significant group of researchers this phenomenon seems ambivalent: having both positive and negative characteristics. According to the cognitive position of cultural constructivism, it is assumed that the subject of the study is an object constituted in scientific consciousness, which is characterized by a set of objective assumptions respected by the researcher. Understanding the content of researchers' statements requires the disclosure of these subject characteristics of the described phenomena and thus the indication of value assumptions constituting the context of the considerations. Here, researchers dealing with the issue of sharing economy recall various culturally embedded - values that positively valorize this phenomenon. Thus, the available methods of explaining the functions and social significance of sharing economy available in the literature are conditioned by normative prejudices. A critical analysis of statements about sharing economy requires an indication of the normative contexts to which they are related. The method used allows: (i) a demonstration of the heterogeneous, dual nature of the sharing economy; (ii) a more detailed explanation of the meaning of this concept by referring to two different ranges of phenomena (entrepreneurship models and forms of social movements); (iii) an explanation of the diversity of assessments of this phenomenon and numerous controversies related to it.

\section{Literature review}

\subsection{Terminological and definitional controversy}

Although this is a relatively new phenomenon, the sharing economy is dynamical and fast-growing in two directions: on the one hand, its area is more and more expanding, thus it becomes a significant field of economy; on the other hand, the sharing economy is definitely a nonhomogeneous area since it is constantly differentiating itself - new forms of this approach continue appearing. As a consequence, there are serious problems with the defining and explaining the idea of sharing economy (Nguyen \& Llosa, 2018). The fundamental problem to be resolved is a terminology-related issue. The researchers who specialise in - to a large extent an intuitively recognized area of phenomena - use various terms: in addition to the term ,sharing economy,' there also appear such terms as: collaborative economy, peer-to-peer economy, collaborative consumption, access economy. Terminological controversy is accompanied by definitional problems - therefore, there is not only the problem with an indication 
of a proper term, but (primarily) with the determining its semantic scope either. A casual analysis of propositions for explanation of the term ,sharing economy' leads to the reflection that they do not allow for extracting even an approximate scope of the phenomena to which it would refer to ${ }^{2}$. It is difficult to relate more broadly to this problem in this text, therefore only several terms (to which some doubts may be expressed if the current state of knowledge was taken into consideration) may be given as an example. Indicating that the sharing economy is 'an economic system based on sharing underused assets or services for free or for a fee, directly from individuals', Botsman (2015) rather refers to the idea (that has been known through centuries) of sharing and bestowing among people who once used to help the needy by means of mutual material assistance or used to facilitate business activity thanks to joint use of tools and machines. This definition certainly lacks in reference to the use of modern information technology enabling to establish contacts ${ }^{3}$. This issue - treated by a majority as an essential characteristic of the sharing economy - was included in E. Aloni's definitions ('an economic activity in which web platforms facilitate peerto-peer exchanges of diverse types of goods and services') quoted from Curtis \& Lehner $(2019$, p. 3) and M. Chenga's ('peer to peer sharing of access to under-utilised goods and services, which prioritizes utilization and accessibility over ownership, either for free or for a fee') quoted from Curtis \& Lehner (2019, p. 3). However, these definitions are limited to the personal exchange, whereas many studies indicate on a great significance of other relations as well: $\mathrm{P} 2 \mathrm{~B}$, B2C, B2B, C2C. There is also a lack in - crucial to many researchers - a characteristic of the sharing economy regarding the use of information technology that is a tool enabling to communicate with the participants in the exchange.

Frenken \& Schor (2017) indicate on the problem with a clear qualification for the sharing economy phenomena and, understanding the term , sharing' in a literal way, admit that they have reasonable doubts whether the situation in which a natural person provides a service on demand, whereas the communication between parties takes place via an online platform e.g. TaskRabbit, should be included. According to the aforementioned authors, paid services should be excluded from the area of sharing economy. In this case, the doubt is related

2 The exception is Wójcik's proposition (quoted from: Czernek et al. (2018, p. 28)) which convincingly makes categorization of the phenomena to which a specific term is attributed. According to Wójcik, the collaborative economy is a basic category that is divided into sectioned subcategories from its area. A similar opinion is expressed by Botsman, (2013, 2015) to whom the sharing economy is a narrower concept than the collaborative economy.

${ }^{3}$ John (2013a, 2013b) points to the strong relationship between sharing economy and modern information technology. He proves that sharing, collaborative consumption is constructed as a high-tech phenomenon. Social networks built online allow the activation of sharing networks in real social life. Furthermore, this impact can be seen already within the language with which the phenomenon of sharing economy is described. According to John (2013a, 2013b), many conceptual categories and metaphors describing the phenomenon of sharing economy originate from the world of high-tech start ups. 
to the authors' explanation of this phenomenon, according to which the sharing economy consists in the mutual sharing (on time-based access) of non-utilised physical resources possible for money. Therefore, the sharing economy is about sharing of goods, but no timesharing or cross-pollination of skills.

Another example explaining the idea of sharing economy is a time-based leasing of living space (house, flat or one room) at a time when owners do not use it. We have here a situation concerning the sharing of access to property. The lease of a house or a flat purchased for purpose of leasing - in opinion of the aforementioned authors - does not meet the criterion of sharing. Furthermore, it should be noted that there are specific and non-obvious instances we encounter in real practice ${ }^{4}$. Interestingly - according to Frenken \& Schor (2017) - the sharing economy should be distinguished from the second-hand economy, which means the exclusion of a whole system of donating unnecessary, non-utilised belongings to the people concerned. It is not the aspect of earning money by selling those belongings, but a matter of literal reference to the term 'sharing' which should be understood in a literal manner: as the (time-based) access to the goods, not as the transfer of property rights to them. Such a standpoint may arouse controversy since the donation of unnecessary belongings to strangers by means of giveboxes or free shops are commonly accepted examples of the sharing economy. Therefore, the idea of sharing should perhaps be comprehended in a broader manner - not only as the joint use, but as the sharing in a sense of donation that is the transfer of belongings to a further use, which represents a specific prolongation of consumption and, hence, an extension of life cycle of a product ${ }^{5}$. Furthermore, if we acknowledge that the sharing economy means the sharing of non-utilised or under-utilised resources in the purpose of extension of productivity or consumer utility, the issue of transferring the property rights is a secondary one. It is also worth - as it seems - including a macro-social dimension, that is the importance of the sharing economy in a general social context. In view of this, we may broaden Frenken's and Schor's range of benefits, given also - beyond the interest of individual parties - the growth of the common good of society.

${ }^{4}$ For example, only the situation of: the purchase of a bigger house with intent to lease its parts of dwelling space; the purchase of a flat intended for a child's needs and leased by parents after the child's emancipation; the lease of an empty flat because of removal; etc. may be indicated. All these instances represent difficulties with respect to decisions, which may be classified as the sharing economy phenomenon.

${ }^{5}$ Belk (2010) presented a very interesting analysis of the content of the concepts of 'sharing', 'gift giving' and 'economic exchange', which allows us to show the specifics of sharing economy in relation to other social practices. In another work, Belk (2014) draws attention to the ambiguity of the term 'sharing'. It refers to both selfless sharing practices and to the market exchange of goods wrapped in a vocabulary of sharing. The positively connoted term refers to practices that have nothing to do with the idea of sharing, which leads to numerous misunderstandings, and above all to the unauthorized positive valuation of activities that mock the commitment to the common good. In essence, Belk deals with the problem of a double face of sharing economy: selfless and profitable activities. 
Given a significant disagreement as to the adopted term and its semantic scope, it appears necessary to make appropriate statements in this regard. At this point I will limit myself to a short explanation why the term sharing economy seems to be convenient. The first argument is prosaic - this argument is used by linguists who accept the use of an expression because of its prevalence. The term , sharing economy' is commonly used and constitutes - as it may be assumed - a long-established element of our communicating about the phenomena related to this non-specific (in the sense of a traditional model) approach to the issue of use of resources. The second argument is substantive in nature and concerns the issue of precise, as much as possible, reference to the existing in the public awareness (professional, journalistic, colloquial) belief in the existence in social practicality a new area of the phenomena to which a specific characteristic is attributed. It was mentioned above that there is a disagreement when it comes to the content of the term we use to indicate this area. However, we may - as it seems - consider that the common element is two constitutive features: (1) the introduction of social exchange of goods and services which have not been utilised before or they were under-utilised (2) the exchange via online platforms or other tools of modern, electronic communication ${ }^{6}$. There is still no consensus on two issues: whether the exchange applies only to peerto-peer relation or whether it may be for fee (cf: Acquier \& Carbone, 2018; Botsman, 2013; Curtis \& Lehner, 2019; Czernek et al., 2018; Lutz \& Newlands, 2018). The controversy associated with this is a consequence of the overlapping of two - adopted to a large extent unknowingly by the majority of authors perspectives in which this phenomenon is analysed. To resolve those issues, the disclosure of assumptions (to which we refer to writing about sharing economy) is required. Let us examine what views and why these particular ones are invoked.

\subsection{Discussions on sharing economy value}

The idea of sharing economy inspires confidence. It is certainly related to a positive connotation of the term ,sharing,' referring to such valuable (in terms of the common good of society) phenomena as: collaboration (necessary for a joint use), coordinating (thus, more an agreement than a conflict or a competition), sharing, donation (then thinking of others), extension of life cycle of products (environmental care in accordance with zero-waste philosophy).

${ }^{6}$ Schor (2016, p. 2) states that the activities concerning the sharing economy possess four categories: circulation of goods, increase in the utility of permanent resources, exchange of services and sharing the means of production. A point of criticism can be made: the circulation of goods is not any exclusive feature of sharing economy, moreover, the circulation is a tool for increasing resource pools used for improving benefits. There is also a lack of clarification in what way the resources are put into circulation. Schor (2016) stresses, after all, that the creation of E-bay and Craiglist platforms in 1995 was the beginning of the sharing economy because those platforms enabled to donate goods, and, as a result, the life cycle of a product has been extended. 
The sharing economy is also positively evaluated because of economic benefits: many reports and prognoses (i.a. PwC (2016), the European Economic and Social Committee, 2016) show that it is a fast-developing economic sector which market share is systematically increasing and may become the driving force for the economic growth in EU countries. We also appreciate the innovativeness and wide flexibility of the sharing economy entities which do not act as traditional organizations responding to a demand, but they adjust their offer to individual customer's needs and, moreover, provide goods and services non-available on the market and thus they compensate for gaps in the satisfaction of specific needs. Another asset of the sharing economy is the possibility of offering diverse goods and services of better quality at a lower price (Grybaitè \& Stankevičienè, 2016, p. 12).

The social aspect of sharing practice is often emphasized, ascribed to the function of building and strengthening interpersonal relationships (Belk, 2010; Botsman, 2013, 2015). According to Belk (2010, p. 717), the source of the tendency to share is the need to be among people identified by sociologists. Sharing goes hand in hand with trust and bonding, which is its distinguishing feature; in contrast with economic transactions that lack the ability to form bonds. On the other hand, the positive impact of sharing economy (as well as collaborative consumption and collaborative economy) on the development of new forms of entrepreneurship is shown (see Czernek et al., 2018; Janczewski, 2017). Sharing economy is also associated with a change in public awareness of excessive consumption and the risks associated with it. The development of social movements identifying with the idea of sharing economy and collaborative consumption is recognized as a consequence of the positive evaluation of these forms of social activities (Albinsson \& Perera, 2012).

It should be noted that positive opinions about the activities of the share economy are not considered by all as reasonable. In-depth analyses show that an intuitively recognized positive value of the sharing economy is not so obvious. Initial enthusiasm for the sharing economy is beginning to be dispelled by research into its real impact on the external environment. Schor (2016) proposes for consideration the belief which attributes to the sharing economy an environmental dimension reflected mainly by the contribution to reducing pollution. According to the above-mentioned author, the belief that the activities concerning the sharing economy remain - in comparison to the classic market activities - a smaller 'carbon footprint', may arise reasonable doubts. In Schor's (2016) opinion, the savings achieved by means of second-hand goods or the use of the cheaper options of services (e.g. Airbnb instead of a hotel) are no guarantee that they will be used for the purchase of eco-friendly products. Also, an easy access to such services as car sharing as an alternative to car ownership will not result in an increase in congestion on the roads and an increase in air pollution. Schor (2016) refers also to the alleged benefits i.e. the creation of social capital, which shall be a consequence of the fact that social contacts have been extended to people out of the friends and family circle (see Cohen \& Kietzmann, 
2014; Schor \& Attwood-Charles, 2017). The author maintains that the research relating to the strengthening acquaintance and friendship ties and the growth of trust level, is inconclusive. Those relations mostly transpire to be occasional thus short-lived, and do not translate into further contacts. Furthermore, not only Schor (2016), but also other researchers (cf: Lutz \& Newlands, 2018) indicate that some discriminatory behaviours, which mainly consist in the exchange made in the circle of representatives belonging to specific races, appear in the area concerning the exchange of goods and services ${ }^{7}$. The tendency to increase profits by increasing fees for arranging in exchange, the competition of platforms, and the attempts of monopolization of the market are evaluated negatively as well.

The agents are also under criticism - the owners of online platforms to whom the objections concerning the working conditions and exploitation of workers, and even their contributing to the expansion of precariat, are formulated (Schor \& Attwood-Charles, 2017). A separate, although very interesting problem related to sharing economy is the problem of privacy - not only personal items introduced to the practice of sharing (car, apartment, home), but also private time spent on activities in the area of sharing economy. In the case of sharing economy, the boundary between what is private and what is professional is not clear-cut (Teubner \& Flath, 2019). The issue of privacy in the context of personal data protection is also a very important issue - participation in various forms of sharing and cooperation requires disclosure of personal data to persons participating in these activities (Ranzini et al., 2017).

According to Schor \& Attwood-Charles (2017), in the history of sharing economy there was a breakthrough dated 2008, which began with the creation of the Airbnb and Uber platforms. In the conviction of the authors cited here, these platforms monetized idle capacity, such as spare rooms, unused cars, spare cars, etc. These were previously lent free of charge, which was a form of neighbourly assistance. Thus, the sharing economy also begins to function as a profitable activity. Many of the popular forms of sharing economy function as both non-profit exchange of goods and services as well as profitable and commercial activity. Examples include coachsurfing and Airbnb, BlaBlacar and Uber, Time Bank aTaskRabbit, Siepomaga.pl and Finansowo.pl. Gradually, the sharing economy understood as business activities began to overshadow the social phenomenon of collaborative consumption.

The economization of the sharing economy therefore leads to problems in its identification: the one term refers to various phenomena. The problem, however, is not only that it defines both nonprofit and profitable activities; but also that similar companies (e.g. Uber and Lyft) have different opinions about their belonging to the sharing economy area. This leads to obvious difficulties in un-

7 Allegations of discriminatory practices within the sharing economy are somewhat misguided. This is not a special feature of this area of activity, but rather a manifestation of discriminatory behavior in contemporary societies caused by well-established social stereotypes. 
derstanding this social phenomenon and causes significant divergences in its assessment (Frenken \& Schor, 2017; Martin, 2016; Reich, 2015).

The improvement of knowledge regarding the sharing economy leads to a paradox: the longer and more intense debate, the more difficult is the consensus of positions for those fundamental issues i.e. the acceptance of a common term, the indication of the semantic scope outlining the area of phenomena to which this concept refers to, and its assessment - social worth and importance. One can even get the impression that the mainstream discussion is focused on the guesses related to attempts to determine the meaning of the concept of sharing economy (cf. Botsman, 2013, 2015; Curtis \& Lehner, 2019; Frenken \& Schor, 2017; Schor \& Attwood-Charles, 2017). Attempts to indicate further criteria (whether it is a profitable activity or not, whether it is a peer-to-peer relationship and the use of online platforms) lead to unsolvable difficulties in determining a reasonably clear boundary of the sharing economy area. Attempts at a more precise specification of sharing economy, however, leads to significant segmentation due to the separation of various categories of phenomena that are associated with sharing economy, but do not have common features. An alternative might be the proposal of a very general and broad definition including all phenomena that meet any criterion (cf. Benkler, 2004), which is not, however, satisfactory due to the generality of the characteristics that do not effectively distinguish between sharing economy activities and other phenomena.

The difficulties identified here regarding the definition of sharing economy are understandable to a degree - we refer to an attempt of conceptualisation of the phenomenon that is developing intensively by the multiplication of its forms. On the other hand - in the case of the sharing economy, those difficulties are in fact a result of the situation of overlapping two phenomena differing in their type and rooted in diverse sets of values. A lack in distinguishing the axiological diversity of these areas leads to the result i.a. that positive connotations concerning the manifestations of activities aimed at the common good of society are automatically transferred to entrepreneurial activities matched to the socalled market logic understood as a narrowly-defined economic rationality.

\subsection{Sharing economy: entrepreneurship model or social movement?}

A condition for explaining the misunderstandings related to the indicated problems is the recognition of two forms of the sharing economy, which in turn requires dating back to the beginning of this phenomenon. There is no doubt that the social movement i.e. the bottom-up, citizens' initiative - a form of activity for which a sense and a primary value is the limitation of consumption, not only in a scale of a single household, but also on a larger social scale - was the beginning. Donation of useful but non-utilised belongings has a twofold benefit: it limits the waste generation and saves resources for the purchase of such goods by a person who benefits from the unpaid offer. In many cases - when the beneficiary is a low-income person, it may be the only opportunity to own those 
belongings. Therefore, the sharing and the mutual donation of goods are also about supporting the needy. Such forms of the sharing economy as giveboxes and free shops may constitute both an assistance in implementing an ecological lifestyle and a form of charity. Another motive of involvement in this type of activities is the building social networks by means of space sharing (co-working, couchsurfing, co-housing) from time to time with the aim of creating a new quality in the system of an open access (guerrilla gardening and social gardens), and also creating the system of a direct link between food suppliers and consumers (food cooperatives). The sharing economy is also a broader concept of the system of mutual material and emotional support, information exchange, knowledge transfer, exchange of services in exclusive, 'thematic' groups of people experiencing the same problems (e.g. the circles of young mothers, parents, the seriously ill and the disabled, feminists). In social terms, it is such a nature of activity by means of which the circulation of goods, services, knowledge and different forms of support occur, as well as the circulation of such activities that lead to the creation of values with an unlimited access. Fair trade and ethical consumption are other related phenomena.

The sharing economy understood as the social movement is an area of such values as: solidarity with people and nature, ecology, responsibility towards future generations, community, respect towards people, value of the property, aware consumption, anti-consumerism, work-life balance, personal relations over material ones, dominance of the value of life over the value of having, the exchange for building networks of unpaid goods and services transactions. A positive tone of the sharing economy is related to the conviction that it enables the implementation of intangible social values to social life, contributing to an increase in the common good of society, the strengthening of the principles of democratic access and the creation of equal opportunities.

Obviously, it should be kept in mind that the construct of social sharing is not the invention of the last twenty-plus years, but it is a practice cultivated for hundreds of years. Before the information revolution, the individuals shared mutually with their goods in the circles of direct acquaintance (family, acquaintances, neighbours). Such type of exchange was based on mutual relations and trust built on direct contacts. Nowadays, online platforms allow for finding a partner in a very convenient and instant manner. Therefore, the area of sharing, exchange and collaboration is substantially extending. The problem of trust is also solved in a different way, which underlies the exchange at least at a minimum level (Czernek et al., 2018; Frenken \& Schor, 2017; Kamal \& Chen, 2016).

We should note that building the sharing networks is not only the issue of opportunities offered by technological development and the means of communication - it is primarily the problem of convictional change which is to some extent a result of globalization. It is about the spread of the awareness of global problems concerning social inequalities and threats relating to environmental pollution and depletion of natural resources. In the case of the sharing economy, it is more about social benefits than individual ones, where a more effective use 
of our (social) assets means the opposition to waste, overconsumption, excessive exploitation of natural resources, limitation of greenhouse gas emissions and also the avoidance of costs related to acquisition and holding. On the other hand, the side effect is building of the networks among individuals not consisting in personal and fixed relations, but rather consisting in the integration around the common values and the strengthening a sense of trust.

Polemically referring to Schor's (2016) notified doubt regarding the sharing economy's positive impact on the level of social capital, it may be stated that there is possible to show a positive interaction - but it should be identified primarily in terms of a general social level. Each fundraising on an important social cause, experience gained by the opportunity of using from various forms of the sharing economy and exchange with people that are not known personally, not only strengthens the conviction in us, but also among those who have indirect knowledge of how an input into such events, which each time prove that it is safe and effective, grows in numbers.

The development of this social movement is accompanied by an intense expansion of the market area, where the idea of access over ownership is used and the opportunities for using modern information technology for building business networks. A network approach, characteristic of 4.0 economy, has been developing simultaneously with the sharing economy and the movement of collaborative consumption, however, for some time there has been a gradual economisation of some forms of the sharing. And that is how the idea of carpooling (e.g. BlaBlacar) that consists in the idea of common car journey in order to decrease the costs, has transformed into the business that is based on the offering of transport services (Uber, itaxi), which in fact have no difference in taxi and transport services (JadeZabiore). The free-of-charge exchange of accommodation in various parts of the world that enables to offer cheaper travelling (couchsurfing) has taken the form of paid, short-term leasing of flats or houses, which is an alternative to the hotel services (Airbnb). The TaskRabbit platform, which offers low-priced services for natural persons and companies, constitutes a counterpart for the idea of free exchange of mutual benefits (a time-based currency). The platform which offers social loans (finansowo.pl) is a business answer for the idea of unpaid supporting of interesting, necessary and worthy projects like crowdfunding (Siepomaga, PolakPotrafi). The axiological context of these activities is: an increase in productivity and consumption, efficiency, flexibility, relations as an instrument, an increase in effectiveness thanks to a better use of resources, the market value of relations and networks, objectification of relations, possession, building networks for exchange. Related phenomena: new economy (4.0 economy), e-business, business networks, development of digital information technology.

The sharing economy may be described as the non-profit area of social activities, which is referred to non-material social values, but it also may be treated as the business model based on information technology and referred to the economic values. The significant problem is that because of identifying 
those two types of phenomena we use the same term, which leads to obvious misunderstandings. To prevent them, we have to decide what we want to discuss and choose an axiological context in which we situate this phenomenon. If we want to analyse the sharing economy as a business model or an individual economic strategy of individuals ${ }^{8}$, the expectations that appear as a result of the projection of the idea of unpaid social movement on the market activity shall not apply. The comments on economization or corporization of the sharing economy make no sense either. The market uses all opportunities for generating profit - it acts in accordance with the assumption about the (economic) rationality - those activities should be thus perceived by the profit rate. The reference to the new forms of entrepreneurship of the beliefs constituting the economy context cooperatively understood as the social movement, results in expressing doubts about their pro-ecological and pro-social value. In a situation where we use one term for two types of activities, we unreasonably transfer that criticism to other forms of the sharing economy. The accusations concerning the excessive stress on profits, the use of an advantage over individual participants in the transaction by means of: pushing high charges for the use of a platform, running the business activity in the informal sector of the economy, etc., strikes at the idea of the social movement of the sharing economy by depreciating it and undermining trust to such forms of collaboration. On the other hand, positive connotations accompanied by the sharing economy referred to business practice may lead to their more favourable treatment, which may result in a breach of confidence in the environment ${ }^{9}$.

The realization that there are two different areas of phenomena that are subject to various normative beliefs and, therefore, to other motives forcing the individuals to the involvement in those activities, is an important issue, both in a theoretical and practical sense. When it comes to conducting research on the sharing economy, a precise definition of the scope of studied phenomena and the setting their characteristics are of the utmost importance. On the other hand, the practical nature requires a legal order (i.a. liabilities to the state) and an ethical order.

\section{Results}

The sharing economy is the subject of a great social interest that is shown both in social practice and scientific research. The purpose of this discussion is to show that in suggested explanations of the term sharing economy, the researchers (often unconsciously) refer to two various axiological contexts, which leads to the thought separation of two categories of phenomena concerning

${ }^{8}$ It is both about an entrepreneurship model consisting in creating platforms intermediating in the market transactions and the use of opportunities in obtaining (basic or additional) income as a service provider.

9 An example of Uber may be mentioned. Its business strategy has caused a lot of controversy regarding i.a. the accusation of unfair competition. 
the sharing economy: a business model and a social movement. We note that depending on what axiological perspective we adopt, we give a different social value for the distinguished categories of phenomena.

Taking into consideration the above-mentioned arrangements, two methods of explaining the term sharing economy may be suggested. The former one refers mainly to the subject of interests of economists who most frequently accept the definition that the sharing economy is an innovative entrepreneurship model based on information technology and consisting in non-utilised or under-utilised resources remaining at the (economic, social) organizations' disposal and household. A constitutive feature of this model is the establishment and the maintenance of relations of: sharing, renting, leasing and exchanging available resources, which - involved in entrepreneurial activities - constitute a source of economic benefits.

The latter way of understanding the term sharing economy shows its social and objective character. From such a perspective, the sharing economy is a mass social movement using modern techniques of communication and its value-sense is the use of resources in a more effective way to broaden the circle of users and to extend the consumption of goods which are at the household's disposal, and to use the potential in terms of offering free-of-charge services. The main motive for activities initiated within the sharing economy framework is the obtaining of (non-financial) utility in a social scale. An increase in social capital is an accompanying effect.

\section{Conclusion}

Summarising the considerations presented above, it is possible to say that an analysis of semantic scope of the term sharing economy, made in different axiological perspectives, leads to the following settling: the recognition of the importance of (values of) social practices defined as the sharing economy should be made in relation to a proper, in terms of research objectives, axiology. An adopted perspective of values-senses allows for a precise indication of area and nature of the examined phenomena consisting in the decision whether the subject of interest is a new entrepreneurship model or whether it is a social movement. The awareness of different expectations towards the sharing economy understood as an innovative business sector or as a pro-developing social movement enables to agree on various arguments positively valorising the both categories of practice.

\section{References}

Acquier, A, \& Carbone, V. (2018). Sharing economy and social innovation. In N.M. Davidson, M. Finck, \& J.J. Infranca (Eds.), The Cambridge handbook of sharing economy and law. Cambridge-New York: Cambridge University Press. doi:10.1017/9781108255882. 
Albinsson, P.A., \& Perera, B.Y. (2012). Alternative marketplaces in the 21st century: building community through sharing events. Journal of Consumer Behaviour, 11(4). doi:10.1002/cb.1389.

Belk, R. (2010) Sharing. Journal of Consumer Research, 35(6). doi:10.1086/612649.

Belk, R. (2014). Sharing versus pseudo-sharing in Web 2.0. Anthropologist, 18(1). doi:10.1080/09720073.2014.11891518.

Benkler, Y. (2004). Sharing nicely: on shareable goods and the emergence of sharing as a modality of economic production. The Yale Law Journal, 114(2). doi: $10.2307 / 4135731$.

Botsman, R. (2013). The sharing economy lakcs a shared definition. Retrieved 15.05.2019 from https://www.fastcompany.com.

Botsman, R. (2015). Defining the sharing economy: what is collaborative consumption and what isn't? Retrieved 02.07.2019 from https://www.fastcompany. com.

Cohen, B., \& Kietzmann, J. (2014). Ride on!: mobility business models for the sharing economy. Organization \& Environment, 27(3). doi:10.1177/1086026614546199.

Curtis, S.K., \& Lehner, M. (2019). Defining the sharing economy for sustainability. Sustainability, 11(3). doi:10.3390/sul1030567.

Czernek, K., Wójcik, D., \& Marszałek, P. (2018). Trust in the sharing economy. Gospodarka Narodowa, 295(3). doi:10.33119/gn/100487.

European Economic and Social Committee. (2016). Opinion of the European Economic and Social Committee on 'Communication from the Commission to the European Parliament, the Council, the European Economic and Social Committee and the Committee of the Regions: a European agenda for the collaborative economy' $(\mathrm{COM}(2016) 356)$.

Frenken, K., \& Schor, J. (2017). Putting the sharing economy to perspective. Environmental Innovation and Societal Transitions, 23. doi:10.1016/j. eist.2017.01.003.

Grybaitė, V., \& Stankevičienè, J. (2016). Motives for participation in the sharing economy: evidence from Lithuania. EkonomiaiZarządzanie, 8(4). doi:10.1515/ emj-2016-0028.

Janczewski, J. (2017). Konsumpcja współdzielona a przedsiębiorczość. Przedsiębiorczość: Edukacja, 13. doi:10.24917/20833296.13.19.

John, N. (2013a). Sharing, collaborative consumption and Web 2.0. Media@ LSE Elactronic Working Paper, 26.

John, N. (2013b). The social logics of sharing. The Communication Review, 16(3). doi:10.1080/10714421.2013.807119.

Kamal, P., \& Chen, J.Q. (2016) Trust in sharing economy. In T.-P. Liang, S.-Y. Hung, P.Y.K. Chau, \& S.-I Chang (Eds.), PACIS 2016 Proceedings. Atlanta: Association for Information Systems.

Lutz, C., \& Newlands, G. (2018). Choice and discrimination in sharing economy. SSRN Electronic Journal. doi:10.2139/ssrn.3241682. 
Martin, C.J. (2016). The sharing economy: a pathway to sustainability or a nightmarish form of neoliberal capitalism? Ecological Economics, 121. doi:10.1016/j.ecolecon.2015.11.027.

Nguyen, S., \& Llosa, S. (2018) On the difficulty to define the sharing economy and collaborative consumption: literature review and and proposing a different approach with the introduction of 'collaborative services'. Journée de la Relation à la Marque dans un Monde Connecté, November.

PwC. (2016). (Wspót)dziel i rządź!: twój nowy model biznesowy jeszcze nie istnieje. Retrieved 02.05.2019 from https://www.pwc.pl.

Ranzini, G., Etter, M., Lutz, C., \& Vermeulen, I. (2017). Privacy in the sharing economy: report from the EU H2020 research project Ps2Share: participation, privacy, and power in the sharing economy. doi:10.2139/ssrn.2960942.

Reich, R.B. (2015) The share-the-scraps economy. Retrieved 06.12.2019 from https://robertreich.org.

Schor, J. (2016). Debating sharing economy. Journal of Self-Governance and Management Economics, 4(3). doi:10.22381/jsme4320161.

Schor, J., \& Attwood-Charles, W. (2017). The 'sharing' economy: labour, inequality, and social connections on for profit platforms. Sociology Compass, 11(8). doi:10.1111/soc4.12493.

Statista. (2019) Retrieved 03.05.2019 from https://www.statista.com.

Teubner, T., \& Flath, C.M. (2019). Privacy in the sharing economy. Journal of the Association for Information Systems, 20(3). doi:10.17705/ljais.00534.

\section{Acknowledgements}

Author contributions: author has given an approval to the final version of the article.

Funding: this research was funded by the Poznan University of Economics and Business, Faculty of Economics, Department of Sociology and Business Ethics statutory sources.

Note: the results of this study were presented at 8th International Scientific Conference: Contemporary Economic Problems 'Social-economic problems in the era of globalization: theory and practice' (May, 22, 2019, Torun, Poland). 
